\title{
Every Child in the World Should Carry a Microscope in Their Pocket
}

\author{
Manu Prakash ${ }^{1}$
}

${ }^{1 .}$ Department of Bioengineering, Stanford University, Stanford, CA, USA

In 2010, I was visiting a health clinic in India and I saw a photo of Mahatma Gandhi looking through a microscope to observe the bacteria that causes leprosy. Gandhi was wearing a dhoti and sitting on the ground, using an expensive European microscope that was impractical for rural India. But Gandhi knew this instrument was needed to help fight disease in his country. This image inspired me to discover new ways to develop low-cost scientific instruments that could be available for everyone, everywhere. Later, while in Thailand, I saw fluorescence microscopes laying on the floor unused because the researchers there were afraid of damaging such expensive equipment.

I decided to build a microscope at a cost of one dollar, yet still have the range of performance necessary to collect useful data. Working on the initial schematics during my flight from Thailand, the first prototype of such an instrument, the Foldscope, became a reality in 2014 [1]. The Foldscope can be assembled in seven minutes from pre-designed, punched cardstock (Figure 1). Folded together using Origami principles, the manually controlled stage has micron-scale positioning control and nanometer scale focusing precision, both by using your thumbs while the instrument is held to your eye. The optical microscope uses a cheap, spherical glass lens and a light emitting diode powered by a watch battery. These microscopes are the size of a bookmark, weigh 8 grams, and can provide magnifications from $140 \mathrm{X}$ up to $2,000 \mathrm{X}$.

Jim Cybulski, my former graduate student and Foldscope co-inventor, founded Foldscope Instruments with me in December 2015. The vision for our company is to widely distribute scientific tools like Foldscope while developing online social platforms like "Microcosmos" [2] to allow information sharing and networking for any curious person interested in scientific exploration. Global distribution of Foldscopes across over 135 countries has allowed many activities, including: identification of microscopic eggs for agricultural pests in India, cataloguing the biodiversity of soil arthropods in the Amazon, detection of fake currency and medicine, and mapping pollen diversity in a city landscape. My hope is to extend "frugal science" in a variety of diagnostic tools, including paper-based centrifuges [3] and even realizing a $\$ 100$ electron microscope.

For children, everything they touch, experience and hold has a microscopic component. Every living thing is made living cells, so just like with astronomy, when you look through a microscope lens, there are galaxies of things crawling around. Growing up in a small town in India, I deeply understand what access to simple but powerful scientific instruments could mean for any kid out there in the world. So, I passionately believe the very real possibility that every child in the world could and should carry a microscope in his/her pocket.

\section{References:}

[1] JS Cybulski, J Clements, and M Prakash, PloS one 9.6 (2014), p. e98781.

[2] M Prakash, Microcosmos, http://microcosmos.foldscope.com/

[3] MS Bhamla et al, Nature Biomedical Engineering 1 (2017), p. 0009. 

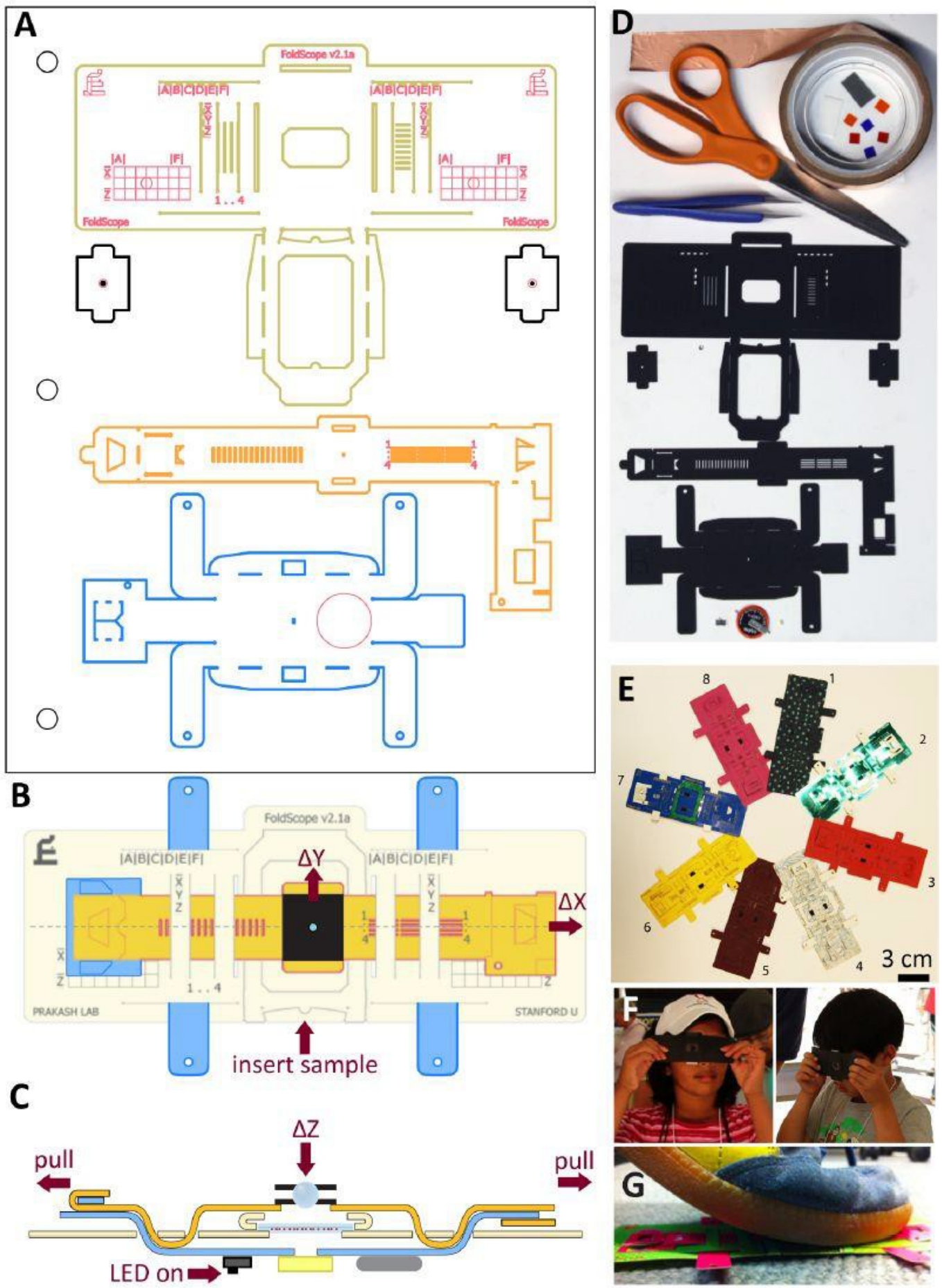

Figure 1. Foldscope design, components and usage. (A) CAD layout of Foldscope paper components on an A4 sheet. (B) Schematic of an assembled Foldscope illustrating panning, and (C) cross-sectional view illustrating flexure-based focusing. (D) Foldscope components and tools used in the assembly, including Foldscope paper components, ball lens, button-cell battery, surface-mounted LED, switch, copper tape and polymeric filters. (E) Different modalities assembled from colored paper stock. (F) Novice users demonstrating the technique for using the Foldscope. $(\mathrm{G})$ Demonstration of the field-rugged design, such as stomping under foot. Reproduced from [1]. 